\title{
Use of HL Cells for Improved Isolation and Passage of Chlamydia pneumoniae
}

\author{
LINDA D. CLES AND WALTER E. STAMM* \\ Department of Medicine and Department of Epidemiology, \\ University of Washington, Seattle, Washington 98195
}

Received 28 November 1989/Accepted 7 February 1990

\begin{abstract}
We compared growth of the recently discovered respiratory pathogen Chlamydia pneumoniae in McCoy, HeLa 229, BHK-21, and HL cells. When cells were not pretreated with DEAE-dextran, HL cells had significantly higher mean numbers of inclusion-forming units (IFUs) on initial inoculation than the other cell lines. When cells were pretreated with DEAE-dextran, HeLa 229 and HL cells had equivalent mean numbers of IFUs on initial inoculation. HL cells had strikingly higher mean numbers of IFUs in passage than HeLa 229, BHK-21, or McCoy cells. In addition, HL cells did not require pretreatment with DEAE-dextran and could be used from 2 to 4 days after seeding. We conclude that HL cells are an excellent cell culture system for laboratory propagation of $C$. pneumoniae and may be a more sensitive cell line for initial isolation.
\end{abstract}

In January of 1989, a new species of the genus Chlamydia was described by Grayston et al. (5). Chlamydia pneumoniae, formerly known as the TWAR agent, was first isolated in 1965 but has only recently been distinguished from Chlamydia trachomatis and Chlamydia psittaci. Previous studies have demonstrated its unique biological characteristics, its genetic distinction from other Chlamydia species, and its importance as a respiratory pathogen $(1,2,4,6,7)$.

$C$. pneumoniae has proved to be a difficult organism to propagate in cell culture. Kuo et al. compared the ability of HeLa 229, McCoy, and L cells to support the growth of two laboratory strains of $C$. pneumoniae and found HeLa 229 cells superior (8). Kappus et al. presented similar findings when comparing HeLa 229 and McCoy cell lines (E. W. Kappus, M. Walsh, and T. C. Quinn, Program Abstr. 27th Intersci. Conf. Antimicrob. Agents Chemother., abstr. no. $729,1987)$. However, even when initial isolation has been achieved, the ability to propagate $C$. pneumoniae in cell culture has been less than satisfactory and little work comparing the effectiveness of various cell lines for passage of $C$. pneumoniae has been done. We report here a comparison of HL cells (a heteroploid line with a slow life cycle that is used for propagating respiratory viruses) with $\mathrm{HeLa} 229$, McCoy, and BHK-21 cells for the isolation and passage of $C$. pneumoniae (3).

\section{MATERIALS AND METHODS}

Chlamydia strains. One $C$. pneumoniae reference strain, TW-183, previously cultivated in HeLa 229 cells, and one $C$. trachomatis reference strain, E/UW-17, previously cultivated in McCoy cells, were studied. Three 10-fold dilutions of each stock strain were prepared in sucrose-phosphateglutamate transport medium.

Cell lines. The four cell lines tested were HeLa 229 (obtained from C.-C. Kuo, Department of Pathobiology, School of Public Health, University of Washington, Seattle), McCoy (from our own laboratory), BHK-21 (ATCC CCL 10; American Type Culture Collection, Rockville, Md.), and HL (obtained from H. F. Maassab, Department of Epidemiology, School of Public Health, University of Michigan, Ann Arbor).

\footnotetext{
* Corresponding author
}

Cell culture of Chlamydia type strains. Our methods for inoculation and growth of Chlamydia strains have been previously described in detail $(8,9,12,15)$. In brief, McCoy, HeLa 229, and BHK-21 cells were seeded into 96-well microtest plates and $15-\mathrm{mm}$ shell vials $24 \mathrm{~h}$ prior to inoculation. HL cells were seeded $48 \mathrm{~h}$ prior to inoculation. Cell monolayers were examined for confluency and were pretreated with DEAE-dextran (molecular weight, $5 \times 10^{5}$ ) (D-9885; Sigma Chemical Co., St. Louis, Mo.; $30 \mu \mathrm{g} / \mathrm{ml}$ ) in Hanks balanced salt solution for $15 \mathrm{~min}$ before inoculation. Comparison plates without DEAE-dextran were treated with Hanks balanced salt solution only. For each experiment, 100 $\mu l$ of each dilution of Chlamydia spp. was inoculated into six wells of a microtest plate and into three shell vials. Cycloheximide (Sigma C-6255; $1.5 \mu \mathrm{g} / \mathrm{ml}$ ) was incorporated into the culture medium (Eagle minimal essential medium [Flow Laboratories, Inc., McLean, Va.] with $10 \%$ fetal bovine serum). Microtest plates and vials were centrifuged at 1,200 $\times g$ at $35^{\circ} \mathrm{C}$ for 60 min (J6-M centrifuge, 4.2 rotor; Beckman Instruments, Inc., Fullerton, Calif.), fresh medium was applied, and the plates were incubated at $36^{\circ} \mathrm{C}$ in $3 \% \mathrm{CO}_{2}$ for $48 \mathrm{~h}$ ( $C$. trachomatis) and $72 \mathrm{~h}$ ( $C$. pneumoniae) prior to staining. Vials were incubated for 3,5 , and 7 days and then sonicated for $10 \mathrm{~s}$, and $2 \mathrm{ml}$ of fresh medium was added. Three microtest wells containing cell monolayers of each of the four test cell lines were inoculated with $100 \mu \mathrm{l}$ from each of the four primary passage vials.

Inclusion stain. We used CF2, a genus-specific, fluorescein isothiocyanate-conjugated monoclonal antibody to Chlamydia lipopolysaccharide (C.-C. Kuo, Department of Pathobiology, School of Public Health, University of Washington, Seattle; available from the Washington Research Foundation, Seattle), to stain inclusions. Inclusions were counted by inverting the plate and scanning each well at a magnification of $\times 10$ with a Neofluor lens and a Zeiss epifluorescence microscope. A $40 \times$ long-working distance lens was used for confirmation.

Statistical procedures. $t$ tests for the differences between means were used for comparison of groups.

\section{RESULTS}

DEAE-dextran enhancement of cell culture. To determine the effect of DEAE-dextran pretreatment on the four cell 
TABLE 1. Comparison of the mean number of $C$. pneumoniae IFUs on initial inoculation by using four different cell lines with and without pretreatment with DEAE-dextran

\begin{tabular}{|c|c|c|c|c|}
\hline \multirow{2}{*}{ Cell line } & \multirow{2}{*}{ Dilution } & \multicolumn{2}{|c|}{ Mean no. of IFUs ${ }^{a}$} & \multirow{2}{*}{ Mean ratio ${ }^{b}$} \\
\hline & & DEAE - & DEAE + & \\
\hline HeLa 229 & $\begin{array}{l}10^{-1} \\
10^{-2} \\
10^{-3}\end{array}$ & $\begin{array}{r}20 \\
140 \\
1,500\end{array}$ & $\begin{array}{r}37 \\
195 \\
2,075\end{array}$ & $1.6^{c}$ \\
\hline McCoy & $\begin{array}{l}10^{-1} \\
10^{-2} \\
10^{-3}\end{array}$ & $\begin{array}{r}17 \\
117 \\
1,104\end{array}$ & $\begin{array}{r}20 \\
137 \\
1,583\end{array}$ & $1.3^{d}$ \\
\hline BHK-21 & $\begin{array}{l}10^{-1} \\
10^{-2} \\
10^{-3}\end{array}$ & $\begin{array}{r}7 \\
71 \\
742\end{array}$ & $\begin{array}{r}9 \\
74 \\
725\end{array}$ & 1.1 \\
\hline HL & $\begin{array}{l}10^{-1} \\
10^{-2} \\
10^{-3}\end{array}$ & $\begin{array}{r}31 \\
210 \\
2,483\end{array}$ & $\begin{array}{r}32 \\
232 \\
2,325\end{array}$ & 1.0 \\
\hline
\end{tabular}

${ }^{a}$ Represents mean of six replicates for each inoculum.

${ }^{b}$ Mean ratio of number of IFUs with DEAE-dextran $(+)$ to that without DEAE-dextran ( - ) for all dilutions.

c $P<0.001$, pretreated versus untreated HeLa 229 cells (all dilutions).

${ }^{d} \boldsymbol{P}=0.02$, pretreated versus untreated McCoy cells (all dilutions)

lines tested, $C$. pneumoniae and $C$. trachomatis were inoculated onto pretreated and untreated monolayers of each cell line. Significant increases in $C$. pneumoniae inclusion counts were seen with pretreated HeLa 229 cells and to a lesser extent with pretreated McCoy cells, but not with pretreated BHK-21 or HL cells (Table 1). In cells not pretreated with DEAE-dextran, the mean number of inclusion-forming units (IFUs) per milliliter of inoculum observed after initial inoculation of $C$. pneumoniae was $2.6 \times 10^{4}$ for $\mathrm{HL}$ cells versus $1.6 \times 10^{4}$ for HeLa 229 cells $(P<0.001)$. Significant increases in $C$. trachomatis inclusion counts were seen in DEAE-dextran-treated HeLa 229 cells but not in the other cell lines (Table 2).

Comparative growth of $C$. pneumoniae and $C$. trachomatis by using HeLa 229, McCoy, BHK-21, and HL cells. Significantly higher $C$. pneumoniae inclusion counts were seen after initial inoculation with both the HeLa 229 and HL cell lines than with McCoy and BHK-21 cells (Table 3). After passage, $C$. pneumoniae propagated for 3,5 , and 7 days in HL cells had strikingly higher inclusion counts than it did in the other cell lines $(P<0.001$ for each comparison; Table 4$)$. Microscropic evaluation of the HL cell monolayers at days 5 and 7 showed many small inclusions indicative of secondgeneration reinfection of the monolayer.

For C. trachomatis, initial inoculation onto HeLa 229, McCoy, and BHK-21 cells produced significantly higher inclusion counts than inoculation onto HL cells (Table 3 ). The highest inclusion counts for $C$. trachomatis in passage were seen when McCoy cells were passed after 3 days of growth, BHK-21 cells were passed after 5 days of growth, and HL cells were passed after 7 days of growth (Table 4).

\section{DISCUSSION}

Grayston, Kuo, Wang, and colleagues have recovered $C$. pneumoniae from patients with acute pharyngitis, bronchitis, sinusitis, and pneumonia $(6,8)$. However, the organism has been considered fastidious, being difficult to recover in initial culture and to maintain and propagate in passage. Thus, improved methods for the isolation and propagation of
TABLE 2. Comparison of the mean number of $C$. trachomatis IFUs on initial inoculation by using four different cell lines with and without pretreatment with DEAE-dextran

\begin{tabular}{lcrrr}
\hline \multirow{2}{*}{ Cell line } & Dilution & \multicolumn{2}{c}{ Mean no. of IFUs ${ }^{a}$} & \multirow{2}{*}{ Mean ratio $^{b}$} \\
\cline { 2 - 4 } HeLa 229 & $10^{-1}$ & 85 & 103 & \\
& $10^{-2}$ & 650 & 746 & $1.2^{c}$ \\
& $10^{-3}$ & 5,300 & 6,225 & \\
McCoy & $10^{-1}$ & 84 & 92 & \\
& $10^{-2}$ & 623 & 633 & 1.1 \\
& $10^{-3}$ & 4,475 & 5,525 & \\
BHK-21 & $10^{-1}$ & 86 & 65 & \\
& $10^{-2}$ & 650 & 654 & 0.9 \\
& $10^{-3}$ & 5,075 & 6,075 & \\
HL & $10^{-1}$ & 54 & 60 & \\
& $10^{-2}$ & 446 & 433 & 1.1 \\
& $10^{-3}$ & 3,525 & 3,850 & \\
\hline
\end{tabular}

${ }^{a}$ Represents mean of six replicates for each inoculum.

${ }^{b}$ Mean ratio of number of IFUs with DEAE-dextran $(+)$ to that without DEAE-dextran $(-)$ for all dilutions.

${ }^{c} \boldsymbol{P}=0.05$, pretreated versus untreated HeLa 229 cells (all dilutions).

C. pneumoniae would be valuable for both clinical and research purposes.

To date, relatively few studies have compared various cell lines and culture techniques for the isolation of $C$. pneumoniae. By using $C$. pneumoniae initially grown in yolk sacs, Kuo et al. reported that initial isolation of $C$. pneumoniae was better in HeLa 229 cells than in McCoy or L cells (8). No data on the efficiency of growth in these cell culture systems after passage were provided (8). Our results confirm their finding that HeLa 229 cells treated with DEAE-dextran were better than McCoy cells for initial isolation of $C$. pneumoniae. Of greater interest, however, was our finding that HL cells consistently demonstrated strikingly higher inclusion counts both upon initial inoculation and after passage than all the other cell lines tested. HeLa 229 cells were particularly poor in enhancing growth of $C$. pneumoniae in passage. These results are particularly striking in view of the fact that the strain we used, TW-183, has been adapted to HeLa cells. Further experience with the use of

TABLE 3. Mean ratio of IFUs observed on initial culture in $\mathrm{HeLa} 229$, McCoy, and HL cells to IFUs observed in BHK-21 cells ${ }^{a}$

\begin{tabular}{lcc}
\hline \multirow{2}{*}{ Host cell } & \multicolumn{2}{c}{ Mean ratio $^{b}$} \\
\cline { 2 - 3 } & C. pneumoniae & C. $^{c}$ trachomatis $^{d}$ \\
\hline BHK-21 & 1.00 & 1.00 \\
HeLa 229 & 3.29 & 1.25 \\
McCoy & 2.10 & 1.10 \\
HL & 3.31 & 0.74 \\
\hline
\end{tabular}

${ }^{a} n=18$ for each cell line and Chlamydia species tested; all experiments used DEAE-dextran pretreatment.

$b$ Mean ratio of IFUs observed on initial culture in HeLa 229, McCoy, and HL cells to IFUs observed in BHK-21 cells.

c $\boldsymbol{P} \leq 0.001$ for all comparisons, with the exception of $C$. pneumoniae growth in HeLa 229 cells compared with that in HL cells (no significant difference).

${ }^{d} P \leq 0.001$ for all comparisons, with the exceptions of $C$. trachomatis growth in BHK-21 cells compared with that in HeLa 229 cells $(P=0.002)$ and growth in BHK-21 or HeLa 229 cells compared with that in McCoy cells (no significant difference). 
TABLE 4. Ratio of Chlamydia IFUs after second passage to IFUs on initial inoculation ${ }^{a}$

\begin{tabular}{lcrr}
\hline \multirow{2}{*}{$\begin{array}{l}\text { Host cell } \\
\text { line }\end{array}$} & $\begin{array}{l}\text { Days of } \\
\text { growth }\end{array}$ & \multicolumn{2}{c}{ Ratio $^{b}$ (no.) $^{c}$} \\
\cline { 2 - 4 } HeLa 229 & 3 & $15.0(9)$ & $55.7(6)$ \\
& 5 & $21.9(9)$ & $30.3(6)$ \\
& 7 & $4.4(9)$ & $8.9(9)$ \\
McCoy & 3 & $258.9(9)$ & $1,153.9(3)$ \\
& 5 & $1,051.0(6)$ & $1,560.0(3)$ \\
& 7 & $274.2(9)$ & $409.9(6)$ \\
BHK-21 & 3 & $60.5(9)$ & $628.8(6)$ \\
& 5 & $434.0(9)$ & $7,055.8(3)^{d}$ \\
& 7 & $52.3(9)$ & $324.6(3)^{e}$ \\
HL & 3 & $336.4(6)$ & $144.7(6)$ \\
& 5 & $2,702.9(3)$ & $2,703.2(3)$ \\
& 7 & $17,252.4(3)^{d}$ & $9,540.6(3)^{d}$ \\
\hline
\end{tabular}

${ }^{a} P \leq 0.001$ for all cell line passage comparisons at 3,5 , and 7 days, with the exception of $C$. trachomatis grown in McCoy cells compared with BHK-21 cells (no significant difference).

${ }^{b}$ Ratio of Chlamydia IFUs after second passage to IFUs on initial inoculation.

${ }^{c}$ Represents number of replicates which could be accurately read in second passage plates.

${ }^{d}$ Reported ratios may be higher because of culture counts too high for accurate assessment.

${ }^{e}$ Reported ratios may be higher because of elementary body cytotoxicity.

HL cells for wild-type strains is needed, but initial experience in our laboratory has demonstrated that HL cells permitted initial recovery and rapid growth in passage of two wild-type $C$. pneumoniae strains recovered from throat swabs.

Unfortunately, none of the cell lines tested were optimal for the isolation and propagation of both $C$. pneumoniae and C. trachomatis. HeLa 229 and McCoy cells have traditionally been used for culturing $C$. trachomatis, with BHK-21 cells being used less frequently. We found that these three cell lines had about equivalent sensitivity for isolation of $C$. trachomatis. However, growth of $C$. trachomatis in HL cells on initial inoculation was clearly inferior to that in the other cell lines tested. Pretreatment of cell lines with DEAEdextran enhanced primary inclusion counts of $C$. trachomatis in HeLa 229 cells, was inconsistent in McCoy and BHK-21 cells (i.e., produced small increases or decreases in inclusion counts at various dilutions with no apparent consistent effect), and resulted in no enhancement in HL cells. Similar results have previously been reported by others $(10$, $11,13,14)$.

In summary, HL cells proved to be the most sensitive of those cell lines tested for the isolation and propagation of $C$. pneumoniae TW-183. In addition, these cells require fewer enhancement procedures, making it easier to work with them. Their sensitivity, for example, was not enhanced by pretreatment with DEAE-dextran, and thus this maneuver can be omitted. HL cell monolayers can also be set up and used from 2 to 4 days after seeding, while HeLa 229 cells must be used within 2 days of seeding. Finally, this cell line allows a specimen with few IFUs to reinfect the same monolayer if it is left intact without repeat centrifugation, thus enhancing recovery in this situation. Further studies with HL cells are needed to determine the optimal concen- tration of cycloheximide, centrifugation speed, and temperature to be used, but our studies indicate that this cell line will be very useful to those studying $C$. pneumoniae and may well provide a more sensitive cell line for diagnostic confirmation of $C$. pneumoniae infection. Clinical studies with $\mathrm{HL}$ cells should be undertaken to assess their relative diagnostic sensitivity by using patient specimens.

\section{ACKNOWLEDGMENT}

This study was supported in part by Public Health Service grant AI-24756 from the National Institutes of Health.

\section{LITERATURE CITED}

1. Campbell, L. A., C.-C. Kuo, and J. T. Grayston. 1987. Characterization of the new Chlamydia agent, TWAR, as a unique organism by restriction endonuclease analysis and DNA-DNA hybridization. J. Clin. Microbiol. 25:1911-1916.

2. Campbell, L. A., C.-C. Kuo, R. W. Thissen, and J. T. Grayston. 1989. Isolation of a gene encoding a Chlamydia sp. strain TWAR protein that is recognized during infection of humans. Infect. Immun. 57:71-75.

3. Cavallaro, J. J., and A. S. Monto. 1971. HL cells, a sensitive line for the isolation and propagation of respiratory syncytial virus. Proc. Soc. Exp. Biol. Med. 140:507-510.

4. Chi, E. Y., C.-C. Kuo, and J. T. Grayson. 1987. Unique ultrastructure in the elementary body of Chlamydia sp. strain TWAR. J. Bacteriol. 169:3757-3763.

5. Grayston, J. T., C.-C. Kuo, L. A. Campbell, and S.-S. Wang. 1989. Chlamydia pneumoniae sp. nov. for Chlamydia sp. strain TWAR. Int. J. Syst. Bacteriol. 39:88-90.

6. Grayston, J. T., C. C. Kuo, S. S. Wang, and J. Altman. 1986. A new Chlamydia psittaci strain, TWAR, isolated in acute respiratory tract infections. N. Engl. J. Med. 315:161-168.

7. Grayston, J. T., C. Mordhorst, A. L. Bruu, S. Vene, and S. S. Wang. 1989. Countrywide epidemics of Chlamydia pneumoniae, strain TWAR, in Scandinavia, 1981-1983. J. Infect. Dis. 159:1111-1114.

8. Kuo, C.-C., H.-H. Chen, S.-P. Wang, and J. T. Grayston. 1986. Identification of a new group of Chlamydia psittaci strains called TWAR. J. Clin. Microbiol. 24:1034-1037.

9. Kuo, C.-C., and J. T. Grayston. 1988. Factors affecting viability and growth in HeLa 229 cells of Chlamydia sp. strain TWAR. J. Clin. Microbiol. 26:812-815.

10. Kuo, C.-C., S.-P. Wang, and J. T. Grayston. 1977. Growth of trachoma organisms in HeLa 229 cell culture, p. 328-336. In D. Hobson and K. K. Holmes (ed.), Nongonococcal urethritis and related infections. American Society for Microbiology, Washington, D.C.

11. Kuo, C. C., S. P. Wang, B. B. Wentworth, and J. T. Grayston. 1972. Primary isolation of TRIC organisms in HeLa 229 cells treated with DEAE-dextran. J. Infect. Dis. 125:665-668.

12. Ripa, K. T. 1982. Microbiological diagnosis of Chlamydia trachomatis infection. Infection 10(Suppl. 1):S19-S24.

13. Ripa, K. T., and P. A. Mardh. 1977. New simplified culture technique for Chlamydia trachomatis, p. 323-327. In D. Hobson and K. K. Holmes (ed.), Nongonococcal urethritis and related infections. American Society for Microbiology, Washington, D.C.

14. Rota, T. R. 1977. Trachoma agent under varying cell culture conditions: infection in McCoy and BHK-21 cells, p. 314-322. In D. Hobson and K. K. Holmes (ed.), Nongonococcal urethritis and related infections. American Society for Microbiology, Washington, D.C.

15. Yoder, B. L., W. E. Stamm, C. M. Koester, and E. R. Alexander. 1981. Microtest procedure for isolation of Chlamydia trachomatis. J. Clin. Microbiol. 13:1036-1039. 